\title{
Diagnostic pitfalls of Cushing syndrome without specific clinical signs among patients with obesity
}

\author{
Volkova N.I., Porksheyan M.I., Ganenko L.A. \\ Rostov State Medical University, Rostov on Don, Russia
}

\section{OBJECTIVES}

Prevalence of CS without specific signs is thought to be high, which might be an indication for its general screening. However, conclusive data about its diagnostics are absent.

\section{METHODS}

\section{RESULTS}
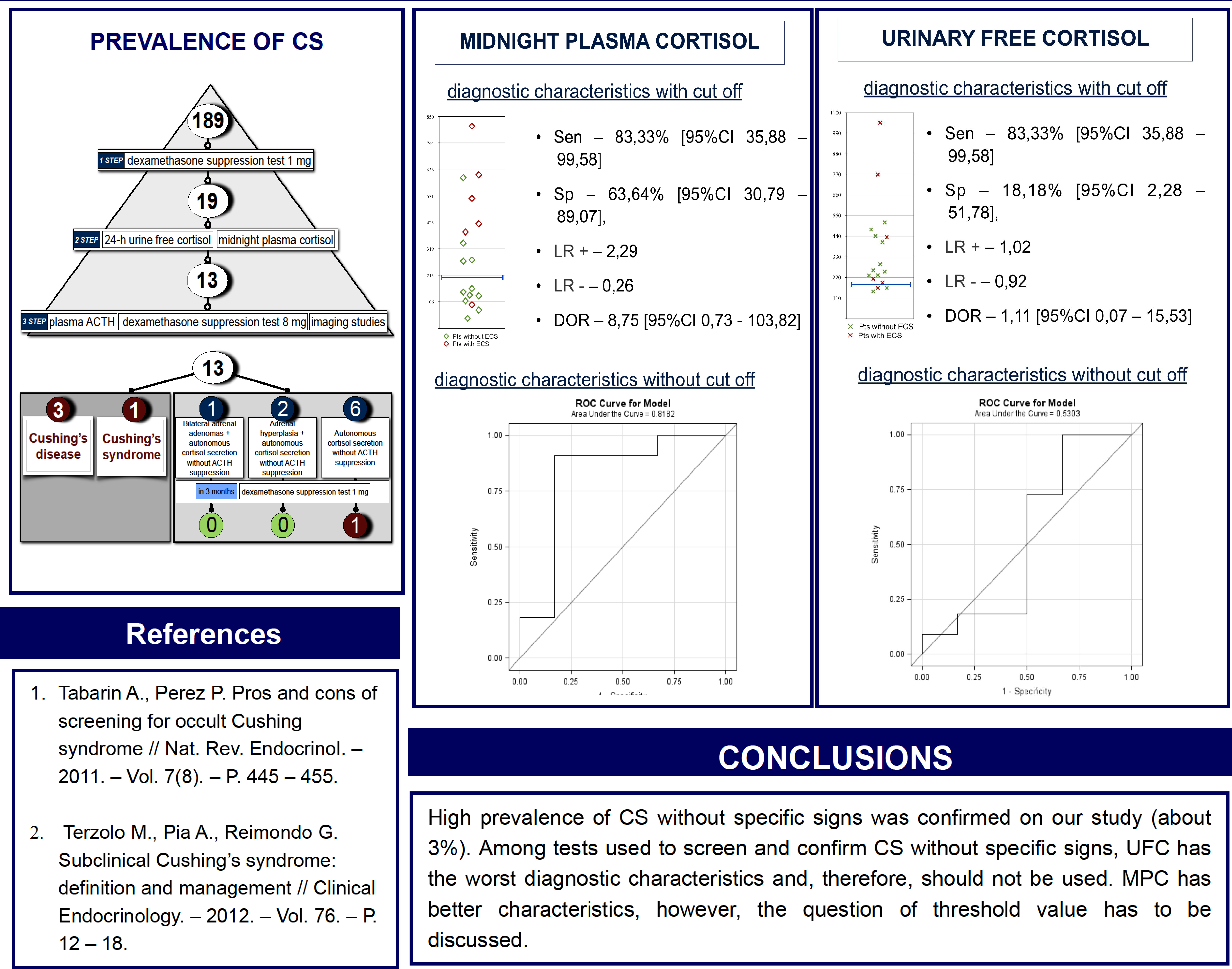

\section{CONCLUSIONS}

High prevalence of CS without specific signs was confirmed on our study (about $3 \%$ ). Among tests used to screen and confirm CS without specific signs, UFC has the worst diagnostic characteristics and, therefore, should not be used. MPC has better characteristics, however, the question of threshold value has to be discussed. 